\title{
Hemin Ameliorated Letrozole-Induced Polycystic Ovary Syndrome: A Forward Step for Better Management
}

\author{
FATMA H. RIZK, M.D. ${ }^{\mathbf{1}}$; NEMA A. SOLIMAN, M.D. ${ }^{\mathbf{2}}$; AMIRA EL-SAADANY, M.D. ${ }^{\mathbf{3}}$; \\ AL-SHIMAA ABO AL-SOUD, M.D. ${ }^{\mathbf{3}}$, MARWA A.A. IBRAHIM, M.D. ${ }^{\mathbf{4}}$ and SHEREEF EL-SHWAIKH, M.D. ${ }^{\mathbf{5}}$ \\ The Departments of Physiology ${ }^{1}$, Medical Biochemistry ${ }^{2}$, Pharmacology ${ }^{3}$, Histology $^{4}$ and Gynecology and Obstetrics ${ }^{5}$, \\ Faculty of Medicine, Tanta University, Egypt
}

\begin{abstract}
Background: Previous studies showed that Heme Oxygenase-1 (HO-1) level was markedly reduced in Polycystic Ovary Syndrome (PCOS) which might highlight the role of $\mathrm{HO}-1$ system in the pathogenesis and treatment of PCOS

Aim of Study: The present study was done to study the effects of the induction of HO-1 system by hemin on Letrozole (LTZ)-induced PCOS in rats.

Material and Methods: 40 female rats were divided into 4 equal groups; normal control (I), hemin (II), LTZ (III), hemin + LTZ treated (IV)

Results: After three weeks, LTZ administration induced PCOS in female rats as evidenced by histological examination and biochemical analysis. It significantly increased testosterone level, $\mathrm{LH}$ and LH/FSH ratio compared with normal control group. LTZ significantly decreased plasma adiponectin level, ovarian Silent Information Regulator 1 level (SIRT1), Glutathione-S-Transeferase activity (GST), HO-1 mRNA expression and ovarian B-Cell Lymphoma 2 (BCL2) expression compared with normal control group. While, it increased ovarian hydrogen peroxide $\left(\mathrm{H}_{2} \mathrm{O}_{2}\right)$ level, ovarian BCL2 associated $\mathrm{X}(\mathrm{Bax})$ expression and $\mathrm{Bax} / \mathrm{Bcl} 2$ ratio compared with normal control group. Hemin administration antagonized all these effects.

Conclusion: We could conclude that, hemin is a promising drug for treatment of PCOS through its antioxidant, antiinflammatory and anti-apoptotic effects which can rise up the possibility of involvement of $\mathrm{HO}$ system in pathogenesis of PCOS.
\end{abstract}

Key Words: Heme oxygenase-1 - Polycystic ovary syndrome - Letrozole.

\section{Introduction}

POLYCYSTIC Ovary Syndrome (PCOS) is an endocrine disorder affecting $5-10 \%$ of the women

Correspondence to: Dr. Fatma H. Rizk, E-Mail: Fatma.rezk@med.tanta.edu.eg in their reproductive period leading to infertility [1]. It can be diagnosed by the presence of at least two of three criteria: Excess androgen, chronic anovulation and polycystic ovary on ultrasound examination [2]. The cause of PCOS remains unclear and it is supposed to be multifactorial involving metabolic, oxidative stress and inflammation [3].

Various experimental models are used to study the pathogenesis and the possible treatment of PCOS. Letrozole (LTZ), a non-steroidal aromatase inhibitor, prevents the conversion of testosterone and androstenedione to estradiol and estrone respectively so it is used to induce a PCOS model that simulates human PCOS [4].

Hemin is produced in the body as a result of the breakdown of hemoglobin. It induces the expression of Heme Oxygenase-1 (HO- 1) [5] . Previous studies proved that hemin exert anti-inflammatory, antioxidant and insulin sensitizing effects through activating HO-1 system in rats [6]. In addition, there are evidences that HO-1levels is markedly reduced in non-obese female with PCOS compared with healthy female which may highlight the role of HO-1 system in pathogenesis and treatment of PCOS [7]. Therefore, the aim of the present experiment was to study the effects of induction of HO1 system by hemin on LTZ-induced PCOS in rats to explore its therapeutic potentials.

\section{Material and Methods}

\section{Drugs and chemicals:}

LTZ (trade name femara ${ }^{\circledR}$ ) was obtained from Novartis Pharma AG, Basle, Switzerland/Suiza in the form of tablet dissolved in normal saline [8] Hemin was obtained from Carbosynth Ltd, [8,9] 
Old Station Business Park, Compton, Berkshire, RG20 6NE, UK. Hemin was dissolved in $0.1 \mathrm{M}$ $\mathrm{NaOH}$, titrated to $\mathrm{pH} 7.4$ with $0.1 \mathrm{M} \mathrm{HCl}$, and diluted 1:10 with phosphate buffer ( $\mathrm{pH} 7.4)$ [9] Chemicals and solvents, used unless otherwise described, were purchased from Sigma (Sigma Chemicals Co., St. Louis, MO, USA). All other chemicals and solvents were of high analytical grade.

\section{Animals:}

Forty female (virgin; isolated since birth) wistar albino rats weighing $170-200 \mathrm{gm}$ were used in the present study. The animals were housed in clean well-ventilated cages, 5 rats in each cage under standard laboratory conditions (12: 12 light-dark cycle, environmental temperature $25 \pm 2^{\circ} \mathrm{C}$ and free access to water and food) and allowed 2 weeks for acclimatization before start of the experiment. All experiments were performed during the same time of the day between 9a.m and 12p.m. The experimental protocol was reviewed and approved by the Animal Care Review Committee at the Faculty of Medicine, Tanta University (approval code no. $32306 / 05 / 18$ ). The experiment was performed in Pharmacology Department, Faculty of Medicine, Tanta University from March 2018 to April 2018.

\section{The rats were randomly divided into 4 groups (10 each): \\ Group I (normal control group): Animals were administered normal saline $0.5 \mathrm{ml} / \mathrm{rat} / \mathrm{day}$ orally by gastric gavage for 3 weeks and hemin vehicle $0.5 \mathrm{ml} / \mathrm{rat}$ by intraperitoneal route twice weekly for 3 weeks starting from first day of experiment.}

Group II (hemin group): Animals were administered hemin $15 \mathrm{mg} / \mathrm{kg}$ intraperitoneal twice weekly for 3 weeks [10].

Group III (LTZ group): Animals were administered LTZ $1 \mathrm{mg} / \mathrm{kg} /$ day orally by gastric gavage for 3 weeks [8]

Group IV (hemin + LTZ treated group): Animals were concomitantly administered LTZ and hemin as described in Group III and Group II respectively.

\section{Blood collection and tissue sampling:}

At the end of the experiment, animals in their estrous phase were timed for scarification guided by a daily vaginal smear [11] which depicted predominant non-nucleated cornified cells while only few leucocytes and epithelial cells were observed Fig. (1A). Blood samples were first taken by cardiac puncture, under light anesthesia by diethyl ether, as previously described by Beeton et al., [12]. Blood was collected into plain EDTA tubes and plasma was separated and stored in aliquots at $-80^{\circ} \mathrm{C}$ till used. After blood sampling, the animals were sacrificed, ovaries were removed, rinsed with saline to eliminate blood contamination and dried by blotting with filter paper then divided into three parts; one part was preserved in $10 \%$ phosphate buffered formalin solution to be processed for histopathological and immunohistochemical examination, and the other parts was then immediately frozen at $-80^{\circ} \mathrm{C}$ for biochemical and molecular analysis.

\section{Preparation of tissue homogenates:}

Pieces of ovarian tissue were homogenized in 5 volumes of $50 \mathrm{mM}$ phosphate buffer ( $\mathrm{pH} 7.4)$ then centrifuged at $11,000 \mathrm{xg}$ for $15 \mathrm{~min}$ at $4^{\circ} \mathrm{C}$. The supernatants were frozen at $-80^{\circ} \mathrm{C}$ until the time of analysis.

\section{Biochemical assays:}

Analysis of plasma hormonal profile:

The plasma levels of testesterone, Lutenizing Hormone (LH) and Follicle-Stimulating Hormone (FSH) were assayed by ELISA technique using commercial supplied kits (Cloud-Clone Corp., Houston, USA) and calculation of FSH/LH ratio. All ELISA techniques were done according to the manufacturer's protocol and read on microplate reader (Stat Fax®2100, Fisher Bioblock Scientific, France), at $450 \mathrm{~nm}$ with correction wavelength set at $570 \mathrm{~nm}$.

Assessment of inflammatory and oxidative stress biomarkers:

Plasma adipnectin and ovarian Silent Information Regulator 1 (SIRT1) levels were assayed using commercial supplied kits (RayBio Inc. Norcross, Georgia, USA, Cloud-Clone Corp., Houston, USA respectively) all ELISA techniques were done according to the manufacturer's protocol and read on microplate reader (Stat Fax®2100, Fisher Bioblock Scientific, France), at 450nm with correction wavelength set at $570 \mathrm{~nm}$. Biochemical assay for tissue Glutathione-S-Transeferase (GST) activity was analyzed as previously described by Habig et al., [13] and hydrogen peroxide level $\left(\mathrm{H}_{2} \mathrm{O}_{2}\right)$ level was analyzed using commercial kit supplied by Biodiagnostic, Co. Giza, Egypt. Protein content was performed according to the method of Lowry et al. [14]

Estimation of ovarian relative heme oxygenase1 (HO-1) mRNA expression by real-time PCR:

Total RNA was extracted from frozen ovarian tissues after processing using Qiagen RNeasy Total 
RNA isolation kit (Qiagen, Hiden, Germany) according to the protocol provided by the manufacturer, followed by synthesis of the first strand using Super-Script III First-Strand Synthesis System for real-time PCR kit (Life Technologies, Carlsbad, California, USA) according to manufacturer's instructions. PCR reactions were performed using Power SYBR Green PCR Master Mix (Life Technologies, Carlsbad, California, USA) following the manufacturer's instructions. HO-1 mRNA transcripts were quantified relative to the housekeeping gene Glyceraldehyde 3-Phosphatede Hydrogenase (GAPDH), which was used as an internal control. Sequence specific primers were designed by Primer 3 software (http://bioinfo.ut.ee/primer3/) as follows: rat HO-1 (NM-012580): Up-stream: 5'- CGTGCAGAGAATTCTGAGTTC-3', down-stream: 5'AGACGCTTTACGTAGTGCTG-3' rat GAPDH (NM_O17008) forward primer (5'GGTGAAGTTCGGAGTCAACGGA-3') and reverse primer CS GAGGGATCTCGCTCCTGGAAGA-3'). The thermal cycling conditions were predenaturation $\left(95^{\circ} \mathrm{C}\right.$ for $5 \mathrm{~min}$ ), followed by 40 cycles of denaturation $\left(95^{\circ} \mathrm{C}\right.$ for $\left.15 \mathrm{~s}\right)$, annealing $\left(60^{\circ} \mathrm{C}\right.$ for $\left.1 \mathrm{~min}\right)$, and extension (72 for 40s). Amplification and data analysis were conducted on a Rotor-Gene Q 6plex and its specific software (Qiagen, Valencia, California, USA). Relative gene expression was automatically calculated using the comparative threshold $(\mathrm{Ct})$ method for the values of the target and the reference genes.

\section{Histological and immunohistochemical study:}

The ovarian specimens were processed to get 5 in paraffin sections and stained with $\mathrm{He}$ matoxylin and Eosin (H \& E) [15].

For immunohistochemical staining, five thick sections were dewaxed and rehydrated to be incubated with $3 \%$ hydrogen peroxide in methanol in humidified chambers to block endogenous peroxidase activity. Antigen retrieval was done by 2 rounds of microwaving for 20 minutes. Sections were then incubated overnight at $4^{\circ} \mathrm{C}$ with rabbit monoclonal anti-BCL2 Associated X (Bax) (ab32503; Abcam, Massachusetts, USA), rabbit polyclonal anti-B-Cell Lymphoma 2 (BCL2) (ab59348; Abcam, Massachusetts, USA). After washing with Phosphate Buffer Solution (PBS), sections were incubated with biotinylated goat anti rabbit secondary antibody for 30 minutes and then with streptavidin peroxidase conjugate for another 30 minutes followed by incubation with Diaminobenzidine (DAB) chromogen to detect immunoreactivity. Mayer's hematoxylin was used for coun- terstaining. Negative controls were done by replacing the primary antibody with PBS [16]

\section{Morphometrical analysis:}

A Leica light microscope (DM500, Swizterland) coupled to a Leica digital camera (ICC50, Swizterland) was used for image acquisition and the software "Image J" (Version 1.48v National Institute of Health, Bethesda, Maryland, USA) was used for image analysis. Ten non-overlapping fields from each slide were examined at a magnification of 400-fold to quantitatively evaluate the following parameters:

1- Mean thickness of granular and theca layer, mean percentage of primary, growing and atretic follicles as well as follicular cysts in relation to the total number of follicles. Additionally, mean ratio of corpora lutea to total number of follicles was recorded.

2- Mean color intensity of positive Bax and Bcl2immunostained cells, it was calculated by subtracting the color intensity of negative immunohistochemical control from the color intensity of positively stained specimens in serial sections. Faint brownish background was not considered a part of the positive reaction and was eliminated during the morphometric analysis. Subsequently, $\mathrm{Bax} / \mathrm{Bcl} 2$ ratio was calculated.

\section{Statistical analysis:}

The data were expressed as the mean \pm SD. Statistical comparison between different groups was carried out using one-way analysis of variance (ANOVA) followed by Tukey test (multiple comparison). Statistical tests were performed with SPSS (IBM SPSS Statistics for Windows, IBM Corp, Version 23.0. Armonk, NY, USA). $p$-values $<0.05$ were considered statistically significant.

\section{Results}

\section{Effect of LTZ and hemin on plasma testosterone,} $L H$ and $F S H$ :

LTZ administration for 3 weeks significantly increased the plasma levels of testosterone, $\mathrm{LH}$, FSH and LH/FSH ratio compared with normal control group. While, concomitant administration of hemin with LTZ significantly decreased them compared with LTZ group and it could restore LH level and LH/FSH ratio to normal values in group IV. Administration of hemin to normal rats did not lead to significant changes in normal values of plasma testosterone, LH and FSH in Group II (Table 1). 
Effect of LTZ and hemin on inflammatory and oxidative stress biomarkers: The administration of LTZ for 3 weeks could significantly increase ovarian ${ }_{\mathrm{H} 2 \mathrm{O} 2}$ levels and significantly decrease plasma adiponectin and ovarian SIRT1 levels, GST activity and HO-1 mRNA expression compared with normal control group. However, concomitant administration of hemin with LTZ could significantly antagonize these effects compared with LTZ group. Ovarian SIRT1 levels were restored to normal level by hemin administration in group IV. Hemin administration to normal rats didn't affect the normal levels of all aforementioned biomarkers in Group II (Table 2).

\section{Histological findings:}

\section{$H \& E$ staining:}

H \& E-stained sections from control Group I showed the normal histological structure of the ovary composed of a cortex covered by germinal epithelium and a medulla with stromal cells and blood vessels in loose connective tissue. The cortex showed ovarian follicles at different stages of maturation embedded in a highly cellular stroma; primary, primordial, growing, and mature Graafian follicles. Multiple corpora lutea were also observed Figs. (1B,C). The primary follicle consisted of an oocyte surrounded by a single layer of squamous follicular cells. The growing follicles had a fluid filled-cavity surrounded by follicular granulosa cells and peripheral fusiform theca folliculi cells Fig. (1D). The Graafian follicles consisted of an oocyte with a well-defined zona pellucida, corona radiata, many layers of granulosa cells, and fusiform theca cells Fig. (1E). Moreover, section from Hemin-treated Group II revealed similar histological findings as the control group Figs. $(1 \mathrm{~F}, \mathrm{G})$.

Examination of $\mathrm{H} \& \mathrm{E}$ stained sections from LTZ Group III revealed multiple stages of follicular development in the ovarian cortex; multiple growing, Graafian follicles and corpora lutea, embedded within an apparently proliferated ovarian stroma. Additionally, multiple follicular cysts and many atretic follicles were detected. Highly vascular medullary stroma could be also observed Figs. $(1 \mathrm{H}, \mathrm{I})$. Some follicles contained numerous cystic preantral cavities, their granulosa cell lining showed signs of vacoulation, some oocytes showed signs of degeneration within the growing follicles Figs. $(1 \mathrm{~J}, \mathrm{~K})$. Some Graafian follicles showed signs of degeneration of oocytes and corona radiate, some follicles were surrounded by thickened granulosa cells with signs of vacuolation. Other follicles showed mixed theca interna and theca externa cells Fig. (1L). Multiple large cystic follicles filled with homogenous pink exudates were observed with attenuated granulosa cell layer, where the inner cells were flat and epithelioid. Many atretic follicles showed dilated antral cavity, thin granulosa cell layers with many apoptotic nuclei, and some granulosa cells were detached into the antral cavity Figs. $(1 \mathrm{M}, \mathrm{N})$.

Examination of $\mathrm{H} \& \mathrm{E}$ stained sections from LTZ and Hemin Group IV revealed a near normal ovarian structure with multiple stages of follicular development in the cortex; multiple growing and Graafian follicles as well as some corpora lutea. Moreover, few follicular cysts and atretic follicles could be detected. Moderately vascular medulla was observed as well Figs. (1O,P).

Morphometrical analysis of the mean thickness of granular layer and theca layer revealed a significant increase in granular layer thickness coupling with a significant decrease in theca layer thickness in Group III compared with the normal control group, while a non-significant difference in both parameters was recorded between Group IV and control group (Table 3).

Morphometrical analysis of the mean percentage of primary and growing (including Graafian) follicles revealed a significant decrease coupled with a significant increase in mean percentage of atretic follicles and follicular cysts in letrozole-treated Group III compared with the normal control group, while there were no significant differences in all parameters between Group IV and normal control group. Moreover, the mean ratio of corpora lutea to total number of follicles showed a significant decrease in Group III compared with the control group, while it did not show significant difference between Group IV and normal control group (Table $3)$.

\section{Bax immunohistochemical staining:}

Bax-immunohistochemical-stained sections from the normal control Group I showed that Bax expression was generally stronger in the granulosa cells than in the theca cells. Bax expression was faint in primary follicles and moderately expressed in growing and Graafian follicles. In contrast, it was intensely expressed in atretic follicles Figs. (2A-C). Moreover, section from Hemin-treated Group II revealed similar immunohistochemical findings as the normal control group Figs. (2D-F). In immune-stained sections from LTZ Group III, primary follicles revealed moderate Bax expression, whereas growing and Graafian follicles depicted variable Bax expression, where Bax was intense 
in granulosa cells, yet it was weak in theca cells. Similarly, it was intensely expressed in both atretic follicles and follicular cysts Figs. (2G-I). On the other hand, immune-stained sections from Group IV depicted moderate expression in primary, growing and Graafian follicles. Yet, intense expression was observed in atretic follicles Figs. (2J-L).

Morphometrical analysis of the mean color intensity of Bax positive immunohistochemical reaction revealed a significant increase in LTZtreated Group III compared with the normal control group, while there did not show significant difference between Group IV and normal control group (Table 3).

\section{Bcl2 immunohistochemical staining:}

Bcl2-immunohistochemical-stained sections from the normal control Group I revealed positive expression of Bcl-2 in granulosa cells at all follicular stages, yet no immunostaining for Bcl-2 was detected in thecal cells. In primary follicles, minimal expression of $\mathrm{Bcl} 2$ was detected. However, intense immunostaining for Bcl-2 was observed in growing, Graafian and atretic follicles Figs.
(3A-C). Moreover, section from Hemin-treated groupII revealed similar immunohistochemical findings as the control group Figs. (3D-F). In LTZ Group III, Bcl-2 expression was either absent in primary, growing and Graafian follicles or weakly expressed in granulosa cells in growing and Graafian follicles. In contrast, atretic follicles showed an intense staining for Bcl-2. Yet, follicular cysts showed a weak expression of Bcl-2 Figs. (3G-I). On the other hand, immune-stained from Group IV depicted minimal to moderate expression of $\mathrm{Bcl} 2$ in primary follicles, moderate to intense expression in growing, Graafian and atretic follicles Figs. (3J-L).

Morphometrical analysis of the mean color intensity of $\mathrm{Bcl} 2$ positive immunohistochemical reaction revealed a significant decrease in LTZtreated Group III compared with the control group, while a non-significant difference was recorded between Group IV and normal control group. Moreover, the ratio of $\mathrm{Bax} / \mathrm{Bcl} 2$ was significantly inversed in the LTZ-treated group but was restored to a near normal value in Group IV (Table 3).

Table (1): Effect of LTZ and hemin on plasma testosterone, LH and FSH.

\begin{tabular}{|c|c|c|c|c|}
\hline Plasma parameters & $\begin{array}{l}\text { Group I } \\
(n=10)\end{array}$ & $\begin{array}{c}\text { Group II } \\
(\mathrm{n}=10)\end{array}$ & $\begin{array}{l}\text { Group III } \\
(n=10)\end{array}$ & $\begin{array}{c}\text { Group IV } \\
(n=10)\end{array}$ \\
\hline Testosterone (pg/ml) & $14.15 \pm 0.47$ & $14.21 \pm 0.44$ & $25.90 \pm 2.34 \mathbf{a}^{\prime} \mathbf{b}$ & $19.30 \pm 0.77^{\mathbf{a}^{\prime} \mathbf{b}^{\prime} \mathbf{c}}$ \\
\hline $\mathrm{LH}(\mathrm{pg} / \mathrm{ml})$ & $6.76 \pm 0.30$ & $6.71 \pm 0.18$ & $12.73 \pm 1.56^{\mathbf{a} \cdot \mathbf{b}}$ & $7.51 \pm 0.57 \mathbf{c}$ \\
\hline FSH (ng/ml) & $3.34 \pm 0.08$ & $3.28 \pm 0.13$ & $3.99 \pm 0.21 \mathbf{a , b}$ & $3.67 \pm 0.29^{\mathbf{a}^{\prime} \mathbf{b}^{\prime} \mathbf{c}}$ \\
\hline $\mathrm{LH} / \mathrm{FSH}$ ratio & $2.02 \pm 0.06$ & $2.05 \pm 0.09$ & $3.19 \pm 0.36^{\mathbf{a}^{\prime} \mathbf{b}}$ & $2.06 \pm 0.24 \mathrm{c}$ \\
\hline $\begin{array}{l}\text { Note: } \\
\text { Data are expressed as m } \\
a: p<0.05 \text { Vs. Group I. } \\
b: p<0.05 \text { Vs. Group II. } \\
c: p<0.05 \text { Vs. Group III. }\end{array}$ & $\pm \mathrm{SD}$ & & & \\
\hline
\end{tabular}

Table (2): Effect of LTZ and hemin on inflammatory and oxidative stress biomarkers.

\begin{tabular}{|c|c|c|c|c|}
\hline Measured parameters & $\begin{array}{l}\text { Group I } \\
(\mathrm{n}=10)\end{array}$ & $\begin{array}{c}\text { Group II } \\
(\mathrm{n}=10)\end{array}$ & $\begin{array}{c}\text { Group III } \\
(\mathrm{n}=10)\end{array}$ & $\begin{array}{c}\text { Group IV } \\
(\mathrm{n}=10)\end{array}$ \\
\hline Plasma adiponectin level (ng/ml) & $3.83 \pm 0.26$ & $3.78 \pm 0.37$ & $2.39 \pm 0.32^{\mathbf{a}} \mathbf{b}$ & $2.99 \pm 0.16^{\mathbf{a}^{\prime} \mathbf{b}^{\prime} \mathbf{c}}$ \\
\hline Ovarian SIRT1 level (ng/mg protein) & $5.31 \pm 0.35$ & $5.20 \pm 0.37$ & $1.73 \pm 0.27^{\mathbf{a}} \mathbf{b}$ & $5.18 \pm 0.32 \mathrm{c}$ \\
\hline Ovarian GST activity (U/mg protein) & $46.20 \pm 2.27$ & $46.38 \pm 2.36$ & $28.83 \pm .29^{\mathbf{a}^{\prime} \mathbf{b}}$ & $39.52 \pm 0.86^{\mathbf{a}, \mathbf{b}, \mathbf{c}}$ \\
\hline Ovarian $\mathrm{H}_{2} \mathrm{O} 2$ level (nmol/gm tissue) & $1.33 \pm 0.09$ & $1.36 \pm 0.22$ & $2.75 \pm 0.31 \mathbf{a}^{\mathbf{a}} \mathbf{b}$ & $1.90 \pm 0.10^{\mathbf{a}^{\prime} \mathbf{b}^{\prime} \mathbf{c}}$ \\
\hline Ovarian relative HO- 1 mRNA expression & $2.05 \pm 0.04$ & $2.08 \pm 0.17$ & $1.22 \pm 0.29 \mathbf{a}^{\prime} \mathbf{b}$ & $1.75 \pm 0.13 \mathbf{a}, \mathbf{b}, \mathbf{c}$ \\
\hline $\begin{array}{l}\text { Note: } \\
\text { Data are expressed as mean } \pm \mathrm{SD} \text {. } \\
\text { SIRT1 : Ovarian tissue silent information regula } \\
\mathrm{H} 2 \mathrm{O} 2 \text { : Hydrogen peroxide level. } \\
\text { GST }: \text { Glutathione-S-Transeferase activity. } \\
\mathrm{HO}-1: \text { Heme Oxygenase- } 1 . \\
\text { a } \quad: p<0.05 \text { Vs. Group I. } \\
\text { b } \quad: p<0.05 \text { Vs. Group II. } \\
\text { c } \quad: p<0.05 \text { Vs. Group III. }\end{array}$ & & & & \\
\hline
\end{tabular}



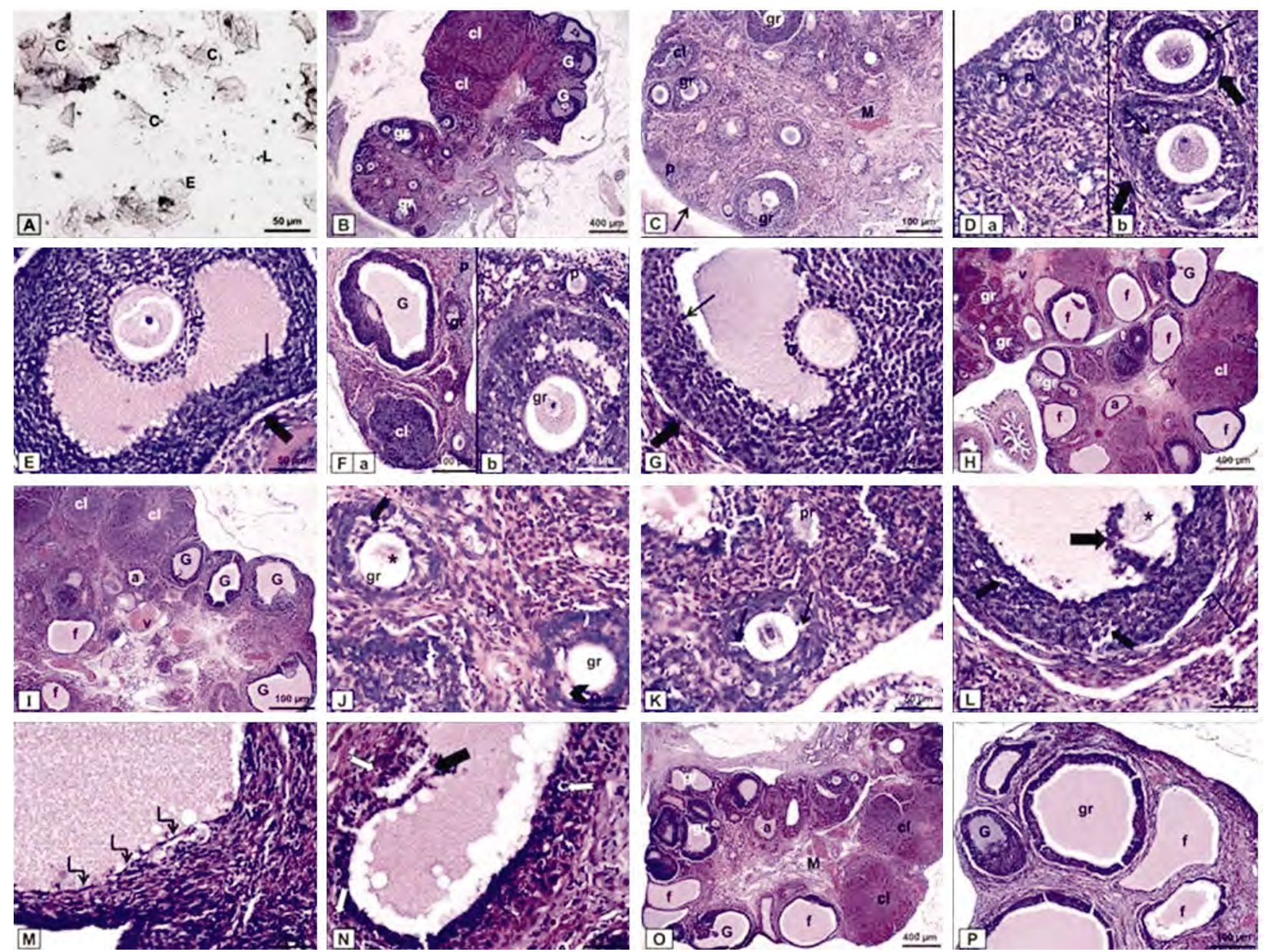

Fig. (1): A) Vaginal smear from estrous phase shows predominant non-nucleated cornified cells (C), few leucocytes (L) and epithelial cells (E).

(B-P) H \& E staining: (B-E) Normal control group; (B, C) Ovarian sections reveal cortex covered by germinal epithelium (arrow) and composed of ovarian follicles at different stages of maturation; primary (p), growing (gr), and mature Graafian follicles (G). Notice corpora lutea (cl). Medulla (M) with stromal cells and blood vessels in loose connective tissue is observed.

(D) a] Primary follicle (p) consisting of an oocyte surrounded by a single layer of squamous follicular cells, b] The growing follicles are composed of a fluid filled-cavity surrounded by follicular granulosa cells (thin arrows) and peripheral fusiform theca folliculi cells (thick arrows).

(E) Graafian follicle is composed of an oocyte with a well-defined zona pellucida (z), corona radiata (c), many layers of granulosa cells (thin arrow), and fusiform theca cells (thick arrow).

(F-G) Hemin-treated group shows ovarian follicles at different stages of maturation; primary (p), growing (gr), and mature Graafian follicles $(\mathrm{G})$ with a well-defined zona pellucida (z), corona radiata (c), many layers of granulosa cells (thin arrow), and fusiform theca cells (thick arrow). Notice corpora lutea (cl).

(H-N) LTZ-treated group; (H,I) Multiple stages of follicular development in the ovarian cortex; multiple growing follicles (gr), multiple Graafian follicles (G) and corpora lutea (cl), embedded within an apparently proliferated ovarian stroma. Additionally, multiple follicular cysts (f) and many atretic follicles (a) are detected. Highly vascular medullary stroma is seen (v).

$(\mathrm{J}, \mathrm{K})$ Primary follicles (p), primordial (pr) and growing follicles ( $\mathrm{gr}$ ) with numerous preantral cavities (arrow head), their granulosa cells lining show vacuolation (notched black arrow), Notice a degenerated oocyte in one growing follicle (asterisk).

(L) Graafian follicle with signs of degeneration of oocyte (asterisk) and corona radiata (thick arrow) surrounded by thickened granulosa cells with signs of vacoulation (notched black arrow). Notice mixed theca interna and theca externa cells (bracket).

(M) Large cystic follicle filled with homogenous pink exudates with attenuated granulosa cell layer, where the inner cells are flat and epithelioid (angular arrows).

(N) Atretic follicle with dilated antral cavity, thin granulosa cell layers with many apoptotic nuclei (notched white arrows), and some granulosa cells are detached into the antral cavity (thick arrow).

(O-P) Group IV; O, P) Multiple stages of follicular development in the ovarian cortex; multiple growing (gr) and Graafian follicles (G). Some corpora lutea (cl) and few follicular cysts (f) and atretic follicles (a) are detected. Notice moderately vascular medulla (M). [Magnifications (A, D, E, Fb, G, J, K, L, M, N X400, scale bar=50 $\mu \mathrm{m}$ ), (B, H, O X40, scale bar=400 $\mu \mathrm{m}$ ) and $(\mathrm{C}, \mathrm{Fa}, \mathrm{I}, \mathrm{P}$ x 100 , scale bar $=100 \mu \mathrm{m})]$. 

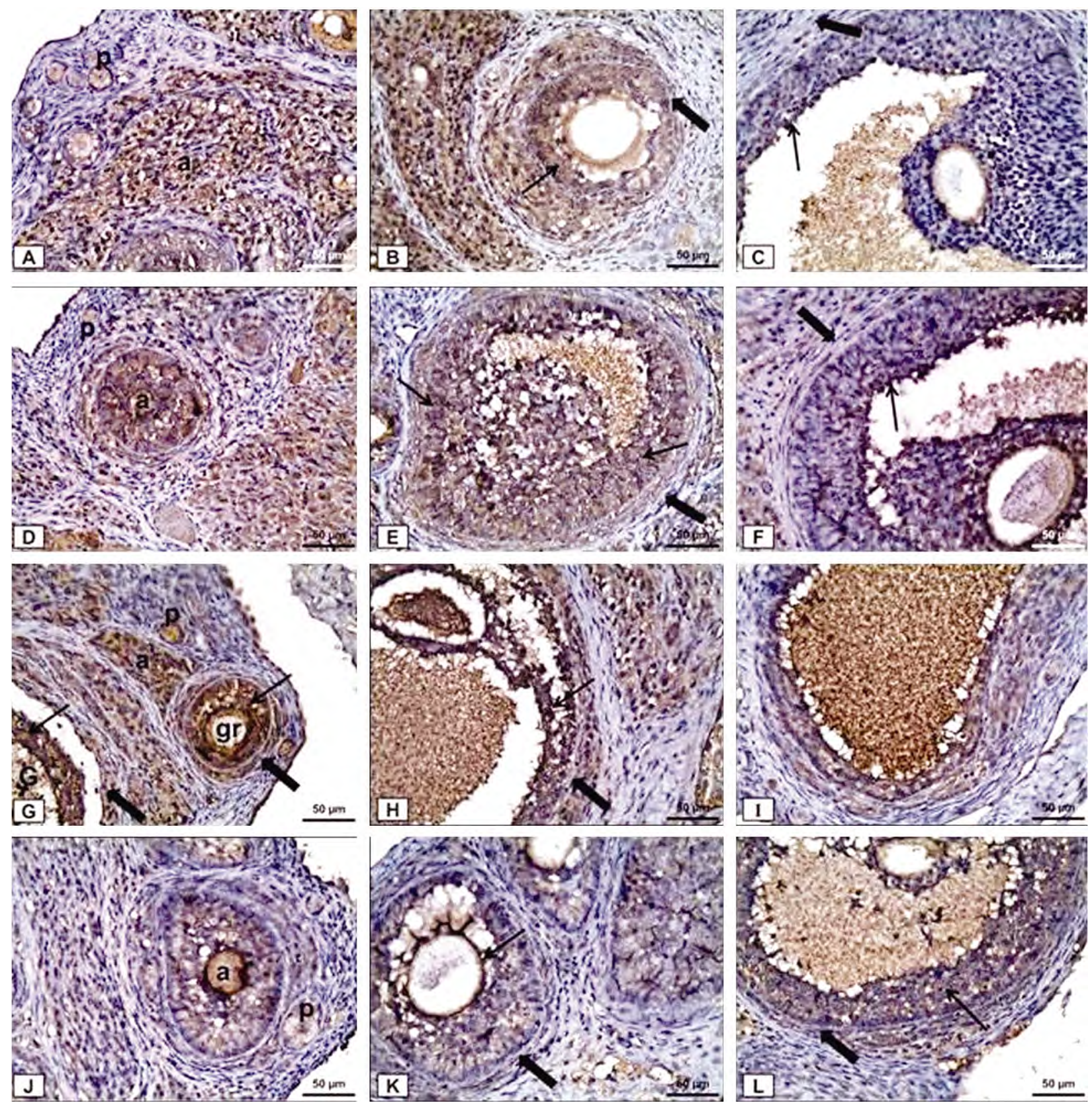

Fig. (2): Bax immunohistochemical staining: (A-C) Normal control Group A) Faint bax expression in primary follicles (p), but intense expression is detected in atretic follicles (a) B) Moderate expression in growing follicles mainly in granulosa cells (thin arrow) rather than theca cells (thick arrow). C) Moderate expression in Graafian follicles mainly in granulosa cells (thin arrow) rather than theca cells (thick arrow).

(D-F) Hemin-treated group shows similar findings as control group (respectively).

(G-I) LTZ-treated group G) Moderate expression in primary follicles (p), intense expression in growing (gr), Graafian (G) and atretic (a) follicles mainly in granulosa cells (thin arrows) rather than theca cells (thick arrows).

(H) Intense expression in Grafian follicles mainly in granulosa cells (thin arrow) rather than theca cells (thick arrow).

(I) Moderate to intense expression in follicular cyst.

(J-L) Group IV J) Moderate expression in Primary follicles (p), intense expression in atretic follicles (a).

(K) Moderate expression in growing follicles in granulosa cells (thin arrow) rather than theca cells (thick arrow).

(L) Moderate expression in Graafian follicles in granulosa cells (thin arrow) rather than theca cells (thick arrow). [Magnification $\mathrm{X} 400$, scale bar=50um]. 

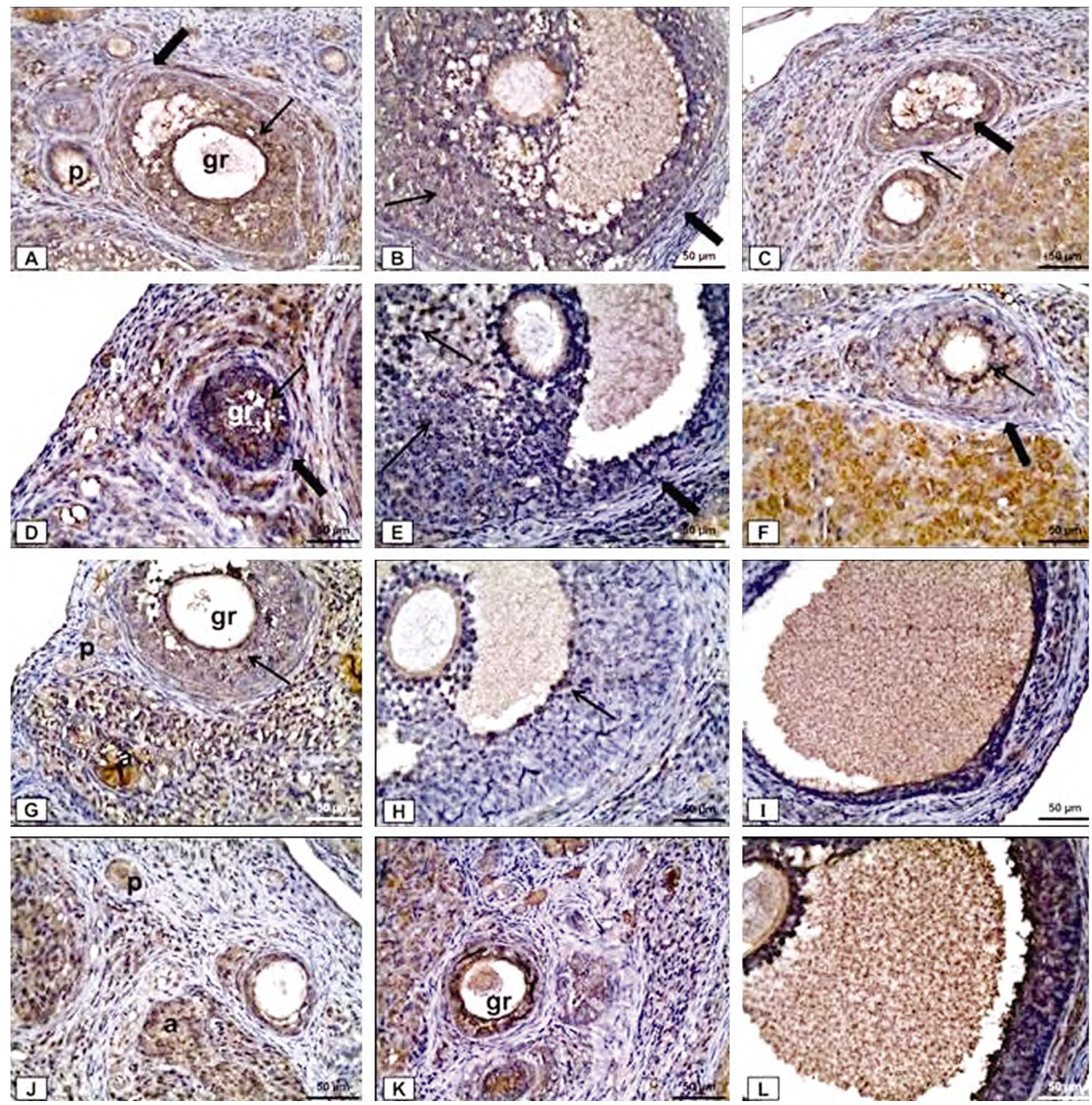

Fig. (3): Bcl2 immunohistochemical staining: (A-C) Normal control Group A) Minimal Bcl2 expression in Primary follicles (p), intense expression in Growing follicles (gr) mainly in granular cells (thin arrow) rather than theca cells (thick arrow).

$(\mathrm{B}, \mathrm{C})$ Intense expression in Graafian and atretic follicles (respectively) mainly in granular cells (thin arrow) rather than theca cells (thick arrow).

(D-F) Hemin-treated group shows similar findings as normal control group (respectively).

(G-I) LTZ-treated group G) Faint/weak expression in Primary (p), growing (gr) follicles mainly in granulosa cells (thin arrow) but intense in atretic follicles (a).

(H) Faint expression in Graafian follicles mainly in granulosa cells (thin arrow).

(I) Weak expression in follicular cyst.

(J-L) Group IV J) Minimal expression in primary follicles (p), moderate expression in atretic follicles (a).

(K) Intense expression in growing follicles (gr).

(L) Intense expression in Graafian follicles. [Magnification X400, scale bar=50 $\mu \mathrm{m}$ ]. 
Table (3): Morphometrical and statistical analysis of different groups.

\begin{tabular}{|c|c|c|c|c|}
\hline Parameters & Group I & Group II & Group III & Group IV \\
\hline Mean thickness of granular layer ( $\mathrm{m})$ & $50.98 \pm 1.45$ & $50.09 \pm 2.44$ & $43.56 \pm 2.14^{\mathbf{a}^{\prime} \mathbf{b}}$ & $48.91 \pm 4.55^{\mathrm{c}}$ \\
\hline Mean thickness of theca layer $(\mathrm{m})$ & $15.87 \pm 1.05$ & $15.04 \pm 1.77$ & $26.99 \pm 2.76^{\mathbf{a}} \mathbf{b}$ & $18.52 \pm 4.08^{c}$ \\
\hline Mean percentage of primary follicles & $46.81 \pm 1.21$ & $46.92 \pm 1.96$ & $41.52 \pm 3.55^{\mathbf{a}} \mathbf{b}$ & $41.87 \pm 7.6^{\mathrm{c}}$ \\
\hline Mean percentage of growing follicles & $34.77 \pm 1.09$ & $34.18 \pm 1.17$ & $16.71 \pm 2.11$ a,b & $31.64 \pm 5.08^{\mathrm{c}}$ \\
\hline Mean percentage of atretic follicles & $18.42 \pm 0.13$ & $18.66 \pm 0.93$ & $21.34 \pm 1.02^{\mathbf{a}^{\mathbf{\prime}} \mathbf{b}}$ & $15.22 \pm 4.88^{\mathrm{c}}$ \\
\hline Mean percentage of follicular cysts & 0.00 & 0.00 & $20.43 \pm 1.88^{\mathbf{a}^{\mathbf{\prime}} \mathbf{b}}$ & $11.27 \pm 1.29 \mathrm{c}$ \\
\hline Mean ratio of corpora lutea to total number of follicles & $0.57 \pm 0.01$ & $0.55 \pm 0.03$ & $0.08 \pm 0.001 \mathbf{a , b}$ & $0.43 \pm 0.02^{c}$ \\
\hline Mean color intensity of Bax immunoreaction & $22.87 \pm 1.99$ & $21.81 \pm 2.11$ & $34.33 \pm 3.76^{\mathbf{a}} \mathbf{b}$ & $25.19 \pm 5.21 \mathrm{c}$ \\
\hline Mean color intensity of $\mathrm{Bcl} 2$ immunoreaction & $41.99 \pm 2.08$ & $41.01 \pm 2.53$ & $28.11 \pm 2.09^{\mathbf{a}} \mathbf{b}$ & $38.02 \pm 5.95^{\mathrm{c}}$ \\
\hline $\mathrm{Bax} / \mathrm{Bcl} 2$ ratio & $0.54 \pm 0.001$ & $0.53 \pm 0.01$ & $1.22 \pm 0.03 \mathbf{a , b}$ & $0.66 \pm 0.42^{c}$ \\
\hline Data are expressed as mean \pm SD. & up III. & & & \\
\hline
\end{tabular}

\section{Discussion}

According to our best knowledge, this is the first study that evaluates the effects of HO1induction on PCOS based on the results of previous study by Gao et al., [7] which showed deficiency of HO-1 level in patients with PCOS.

LTZ administration could induce a model of PCOS in female rats as evidenced by histological examination of ovaries and biochemical analysis of plasma hormonal profiles. It significantly increased testosterone level, $\mathrm{LH}$ and $\mathrm{LH} / \mathrm{FSH}$ ratio. LTZ is a competitive inhibitor to aromatase enzyme by binding to heme subunit of cytochrome $\mathrm{p} 450$ [17] which subsequently decreases estrogen and increases the ovarian androgens which leads to hyperandrogenism and abnormal follicular development [18]. The ovarian androgen increases the number of pycnotic granulosa cells and degenerates oocytes [19].

Moreover, testosterone secretion by theca cells is stimulated in this condition might be attributed to the increase of LH level. Pituitary production of LH is increased because of the decreased estrogen production with LTZ administration and subsequently weakens the negative feedback exerted by estrogen on LH production in pituitary gland [4]. Increased LH and LH/FSH ratio are the main factors contributing to the anovulatory state in PCOS as LH increases ovarian androgen which suppresses follicle growth and maturation [20]

However, concomitant administration of hemin along with LTZ could significantly antagonize histological and biochemical abnormalities induced by LTZ. Hemin normalized mean thickness of granular layer, mean thickness of theca layer, mean percentage of primary follicles, mean percentage of growing follicles, mean percentage of atretic follicles, mean percentage of follicular cysts and mean ratio of corpora lutea to total number of follicles. These effects might be due to its ability to significantly reduce testosterone level and normalize $\mathrm{LH}$ and $\mathrm{LH} / \mathrm{FSH}$ ratio.

In addition, the results of the present study showed that LTZ administration decreased plasma adiponectin level. This could be explained by previous studies which showed that testosterone has a down regulatory role on adiponectin secretion [21]. While, hemin administration in the present work showed that it could significantly increase plasma adiponectin level. Adiponectin is a protein secreted from adipose tissue and has insulin sensitizing effects as it enhance glucose transport via glucose transporter 4 (GLUT4) [22], and fatty acid oxidation [23]. Low plasma level of adiponectin has been associated with Insulin Resistance (IR) [24]. Moreover, previous studies proved that HO1 enhances insulin sensitivity and decreases insulin levels [25] as it increases adiponectin level [26] and suppresses nuclear-factor kappa B (NF- $\mathrm{KB}$ ) and cJun-N-terminal kinase (JNK) that are considered as insulin inhibitory pathways through its ability to block insulin synthesis and induce IR [27]. IR with hyperinsulinemia enhances LH and gonadotropin-releasing hormone (GnRH) in PCOS [28] Also, insulin could enhance the biosynthesis of testosterone in theca cells by affecting the expression of low density lipoprotein cholesterol receptors in granulosa cells [29]

Moreover, oxidative stress is considered as one of the possible mechanisms involved in increased testosterone production in PCOS [30]. The results of the present study showed that LTZ administration reduced ovarian antioxidants including GST enzyme activity and relative HO-1 mRNA expression and increased the ovarian oxidant ${ }_{\mathrm{H} 2 \mathrm{O} 2}$ level. The increased oxidant level may induce testosterone production and PCOS by altering steroidogenesis [31]. In addition, the oxidative stress induces in- 
flammatory state that may contribute to IR and hyperandrogenism in patients with PCOS [32].

LTZ-induced inflammatory state was proved in the present study as LTZ decreased ovarian SIRT1 level compared with normal control group. SIRT1 exerts anti-inflammatory effects as it enhances macrophage polarization into the M2 phenotype with its ability to suppress inflammation [33]. Also, it can inhibit nuclear-factor kappa B (NF- $\kappa B$ ) [34] and Peroxisome Proliferator-Activated Receptor g (PPARg) [35]. PCOS is characterized by a vicious circle of IR, oxidative stress and chronic inflammation [32]

In addition, LTZ administration significantly enhanced the occurrence of apoptosis in ovarian tissues and affected the related protein expression as it increased $\mathrm{Bax}$ expression and $\mathrm{Bax} / \mathrm{Bcl} 2$ ratio but it decreased $\mathrm{Bcl} 2$ expression in ovarian tissue compared with normal control group. Cell apoptosis has an essential role in follicular development, oocyte degeneration, follicle selection and follicle atresia. PCOS patients show dysregulation of cell apoptosis [36] which could be due to dysregulation of FSH-granular cell axis with elevation of androgen level leading to impairment of follicle selection and aggregation of small follicles to form cysts inside the ovary [37].

While, hemin administration in the present study could significantly suppress LTZ-induced oxidative stress, inflammation and apoptosis. It increased ovarian antioxidants including GST enzyme activity, up regulated the relative $\mathrm{HO}-1$ mRNA expression, decreased the ovarian oxidant $\mathrm{H}_{2} \mathrm{O}_{2}$ level, normalized Ovarian SIRT1 level, Bax expression, $\mathrm{Bax} / \mathrm{Bcl} 2$ ratio and $\mathrm{Bcl} 2$ expression in ovarian tissue compared with LTZ group. Hemin induces $\mathrm{HO}-1$ that catalyzes degradation of heme into iron, $\mathrm{CO}$ and Bilirubin. Iron enhances the synthesis of ferritin and antioxidants. In addition, $\mathrm{CO}$ and bilirubin suppress oxidative stress, inflammation and apoptosis [27].

\section{Conclusion:}

HO-1 induction by hemin has beneficial effects in treatment of LTZ-induced PCOS in rats through its antioxidant, anti-inflammatory and anti-apoptotic effects which rise up the possibility of involvement of $\mathrm{HO}$ system in pathogenesis of PCOS. Future studies are needed to evaluate the effects of hemin on treatment of PCOS patients and compare its effects with the standard medical treatment.

\section{Conflict of interest:}

The authors declare that there is no conflict of interest associated with this work.

\section{References}

1- NORMAN R.J., DEWAILLY D., LEGRO R.S. and HICKEY T.E.: Polycystic ovary syndrome. Lancet, 370 (9588): 685-97, 2007.

2- HOMBURG R.: Polycystic ovary syndrome. Best Pract. Res. Clin. Obstet. Gynaecol., 22 (2): 261-74, 2008.

3- ZUO T., ZHU M. and XU W.: Roles of Oxidative Stress in Polycystic Ovary Syndrome and Cancers. Oxid. Med. Cell. Longev., 2016:8589318, 2016.

4- KAFALI H., IRIADAM M., OZARDALI I. and DEMIR N.: Letrozole-induced polycystic ovaries in the rat: A new model for cystic ovarian disease. Arch. Med. Res., 35: 103-8, 2004.

5- HUALIN C., WENLI X., DAPENG L., XIJING L., XIUHUA P. and QINGFENG P.: The anti-inflammatory mechanism of heme oxygenase-1 induced by hemin in primary rat alveolar macrophages. Inflammation, 35 (3): 1087-93, 2012.

6- SAAD A.H., IBRAHIM H.M., NAZMY W.H. and HUSSEIN A.: Induction of Heme Oxygenase-1 Improves Glucose Tolerance and Enhances Insulin Sensitivity in Obese Diabetic Rats. Journal of Advances in Medical and Pharmaceutical Sciences, 10 (3): 1-11, 2016.

7- GAO H., MENG J., XING H., NIE S., XU M., ZHANG S., JIN Y., SUN T., HUANG H., ZHANG H., WANG D., LIU L., et al.: Association of heme oxygenase-1 with the risk of polycystic ovary syndrome in non-obese women. Hum. Reprod., 29 (5): 1058-662014, 2014.

8- NOORAFSHAN A., AHMADI M., MESBAH S.F. and KARBALAY-DOUST S.: Stereological study of the effects of letrozole and estradiol valerate treatment on the ovary of rats. Clin. Exp. Reprod. Med., 40 (3): 11521, 2013.

9- JADHAV A., TORLAKOVIC E. and NDISANG J.F.: Interaction among heme oxygenase, nuclear factor-kappa $\mathrm{B}$, and transcription activating factors in cardiac hypertrophy in hypertension. Hypertension, 52: 910-7, 2008.

10-NDISANG J.F. and JADHAV A.: Heme oxygenase system enhances insulin sensitivity and glucose metabolism in streptozotocin-induced diabetes. Am. J. Physiol. Endocrinol. Metab., 296 (4): E829-41, 2009.

11- MARCONDES F.K., BIANCHI F.J. and TANNO A.P.: Determination of the estrous cycle phases of rats: Some helpful considerations. Braz. J. Biol., 62 (4A): 609-14, 2002.

12- BEETON C., GARCIA A. and CHANDY K.G.: Drawing blood from rats through the saphenous vein and by cardiac puncture. J. Vis. Exp., (7): 266, 2007.

13- HABIG W.H., PABST M.J. and JOKOBY W.B.: Glutathione S-transferase: The first enzymatic step in mercapturic acid formation. J. Biol. Chem., 249: 7130-9, 1974.

14- LOWRY O.H., ROSENBROUGH N.G., FARR A.L. and RANDALL R.J.: Protein measurements with the Folin phenol reagent. J. Biol. Chem., 193 (1): 265-75, 1951.

15- BANCROFT J.D. and GAMBLE M.: Theory and Practice of Histological Techniques. Six th ed. Philadelphia: Churchill Livingstone: Elsevier. 126-7, 2008. 
16- BUCHWALOW I.B. and BÖCKER W.: Immunohistochemistry: Basics and Methods. Springer, Heidelberg, Dordecht, London, New York, 31-9, 2010.

17- BUZDAR A.U., ROBERTSON J.F., EIERMANN W. and NABHOLTZ J.M.: An overview of the pharmacology and pharmacokinetics of the newer generation aromatase inhibitors anastrozole, letrozole and exemestane. Cancer, 95 (9): 2006-16, 2002.

18- DIAMANTI M., LAMB H.J., REE M.A., ENDERT E.L., GROENEVELD Y. and BOTS M.L.: The association between abdominal visceral fat and carotid stiffness is mediated by circulating inflammatory markers in uncomplicated type 2 diabetes. J. Clin. Endocrinol. Metab., 90: 1495-01, 2005.

19- MORALES-LEDESMA L., DÍAZ RAMOS J.A. and TRUJILLO HERNÁNDEZ A.: Polycystic ovary syndrome induced by exposure to testosterone propionate and effects of sympathectomy on the persistence of the syndrome. Reprod. Biol. Endocrinol., 10: 15 (1): 50, 2017.

20- The Japanese Society of Obstetrics and Gynecology (JSOG): Constitute of Reproductive rndocrinology. Reports of a new diagnostic criteria of PCOS in Japan. Acta Obstet. Gynecol. Jpn., 59: 868-86, 2007.

21- LANFRANCO F., ZITZMANN M., SIMONI M. and NIESCHLAG E.: Serum adiponectin levels in hypogonadal males: Influence of testosterone replacement therapy. Clinical Endocrinology (Oxford), 60: 500-7, 2004.

22- GUO Z., XIA Z., YUEN V.G. and McNEILL J.H.: Cardiac expression of adiponectin and its receptors in streptozotocin-induced diabetic rats. Metabolism, 56: 1363-71, 2007.

23- KIM J.Y., VAN De W.E., LAPLANTE M., AZZARA A., TRUJILLO M.E., HOFMANN S.M., et al.: Obesityassociated improvements in metabolic profile through expansion of adipose tissue. J. Clin. Invest., 117: 262137, 2007.

24- TATARANNI P.A.: Hypoadiponectinemia in obesity and type 2 diabetes: Close association with insulin resistance and hyperinsulinemia. J. Clin. Endocrinol. Metab., 86: 1930-5, 2001.

25- NICOLAI A., LI M., KIM D.H., PETERSON S.J., VANELLA L., POSITANO V., et al.: Heme oxygenase-1 induction remodels adipose tissue and improves insulin sensitivity in obesity-induced diabetic rats. Hypertension, 53: 508$15,2009$.

26- NDISANG J.F., LANE N., SYED N. and JADHAV A.: "Up-regulating the heme oxygenase system with hemin improves insulin sensitivity and glucose metabolism in adult spontaneously hypertensive rats,". Endocrinology, 151 (2): 549-60, 2010.
27- NDISANG J.F.: Role of Heme Oxygenase in Inflammation, Insulin-Signalling, Diabetes and Obesity. Review Article. Mediators of Inflammation: 1-18, 2010.

28- ROJAS J., CHAVEZ M. and OLIVAR L.: Polycystic Ovary Syndrome, Insulin Resistance, and Obesity. Navigating the Pathophysiologic Labyrinth. Int. J. Reprod. Med., 2014: 1-17, 2014.

29- BLANK S.K., McCARTNEY C.R., CHHABRA S., HELM K.D., EAGLESON C.A., CHANG R.J., et al.: Modulation of gonadotropin-releasing hormone pulse generator sensitivity to progesterone inhibition in hyperandrogenic adolescent girls--implications for regulation of pubertal maturation. J. Clin. Endocrinol. Metab., 94 (7): 2360-6, 2009.

30- LIU J. and ZHANG D.: The role of oxidative stress in pathogenesis of polycystic ovary syndrome. Sichuan Da Xue Xue Bao Yi Xue Ban, 43 (2): 187-90, 2012.

31- SABUNCU T., VURAL H. and HARMA M.: Oxidative stress in polycystic ovary syndrome and its contribution to the risk of cardiovascular disease. J. Clin. Biochem., 34 (5): 407-13, 2001.

32- GONZÁLEZ F., ROTE N.S., MINIUM J. and KIRWAN J.P.: Reactive oxygen species-induced oxidative stress in the development of insulin resistance and hyperandrogenism in polycystic ovary syndrome. J. Clin. Endocrinol. Metab., 91 (1): 336-40, 2006.

33- PARK S.Y., LEE S.W., LEE S.Y., HONG K.W., BAE S.S., KIM K., et al.: SIRT1/Adenosine MonophosphateActivated Protein Kinase a Signaling Enhances Macrophage Polarization to an Anti-inflammatory Phenotype in Rheumatoid Arthritis. Front. Immunol., 8: 1135, 2017.

34- YOSHIZAKI T., MILNE J.C., IMAMURA T., SCHENK S., SONODA N., BABENDURE J.L., et al.: SIRT 1 exerts anti-inflammatory effects and improves insulin sensitivity in adipocytes. Mol. Cell. Biol., 29 (5): 1363-74, 2009.

35- PICARD F., KURTEV M., CHUNG N., TOPARKNGARM A., SENAWONG T., MACHADO De OLIVEIRA R., et al.: Sirt1 promotes fat mobilization in white adipocytes by repressing PPAR-gamma. Nature., 429: 771-6, 2004.

36- BAS D., ABRAMOVICH D., HERNANDEZ F. and TESONE M.: Altered expression of Bcl-2 and Bax in follicles within dehydroepiandrosterone-induced polycystic ovaries in rats. Cell. Biol. Int., 35: 423-9, 2011.

37- JONARD S. and DEWAILLY D.: The follicular excess in polycystic ovaries, due to intra-ovarian hyperandrogenism, may be the main culprit for the follicular arrest. Hum. Reprod Update, 10: 107-17, 2004. 


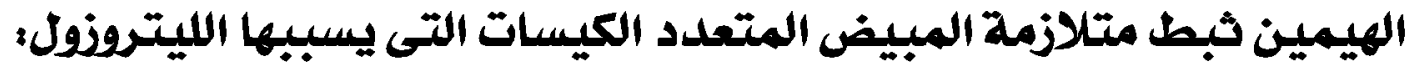

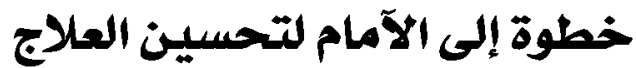

هدف البحث: يهدف هذا البحث إلى دراسة تآثيرات إستحداث نظام الهيم آوكسينيز بواسطة الهيمين على متلازمة المبيض المتعدد الكيسات في الفئران.

الطريقة: تم تقعيم • ع من إناث الفئران إلى آربعة مجموعات متساوية كما يآتى: • المجموعة الآولى: مجموعة طبيعية ضابطة. • المجموعة الثانية: مجموعة الهيمين.

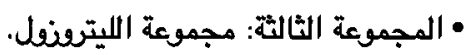

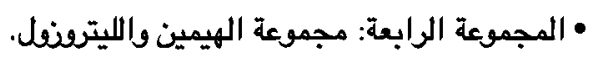

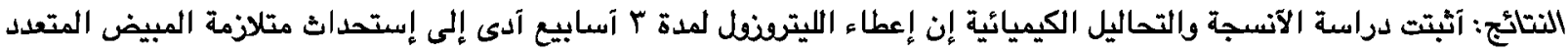

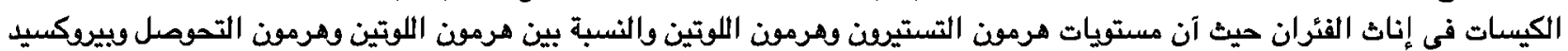

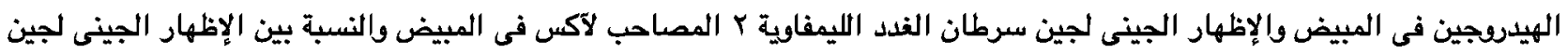

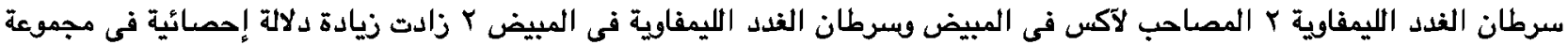

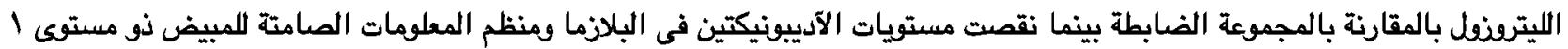

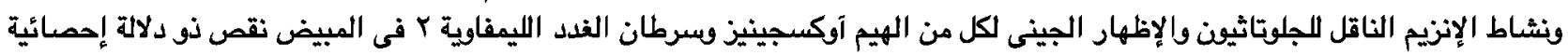

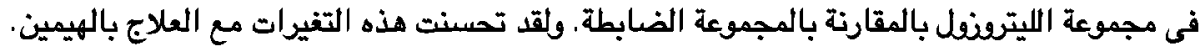

الخلاصة:نستخلص من كل ما سبق إن الهيمين يمكن إعتباره من الآدوية التى يمكن إستعمالها لعلاج متلازمة المبيض المتعدد الكيسات

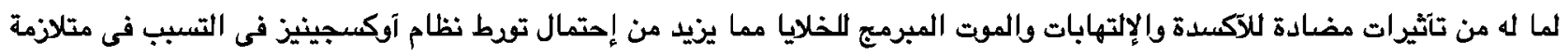
تكيس المبايض. 